\title{
Quality of Medical Service and Purchase Intention: A Conceptual Framework and Empirical Evidence
}

\author{
Min-Sook Kim and Ho-Yeol Bang \\ Dept. of Economic and Commerce, Keimyung University \\ 1095, Dalseo-Gu, Daegu 704-701, KOREA \\ kms@gw.kmu.ac.kr \\ Dept. of Business, Pusan National University \\ Geumjeong-gu, Busan 609-735, KOREA \\ Corresponding Author: hybang@pusan.ac.kr
}

\begin{abstract}
Existing studies have presented a wide range of factors determining the quality of medical service. No studies tried integrating and classifying them in a systematic and concise way. This paper presents a conceptual framework for organizing various determinant factors into three hierarchical categories, and examines the categories' influences on a customer's intention to purchase a medical service. Empirical analysis was done by using data from Chinese medical tourists in Korea. The role of an invasiveness of treatment is additionally explored as a moderating variable in order to examine the relative importance of influencing factors. Depending on the type of medical services to be purchased, an invasiveness of treatment will play a moderating role between the quality of medical service and customer's purchase intention.
\end{abstract}

Keywords: medical service quality, medical tourism, SERVQUAL model, invasiveness, core Service, augmented service

\section{Introduction}

Diverse topics were studied related with medical tourism. One of them is about exploring the factors which constitute the quality of medical service, and their relationships with customer's intention to purchase. Existing studies on this topic suggested a wide range of factors constituting the quality of medical service. The studies can be divided into three research streams.

The first one utilized the components of the SERVQUAL model (Parasuraman, et al., $1985,1988)$ to measure the quality of medical services. The SERVQUAL model has been widely used in a service industry to measure the quality of service. The model was borrowed to measure the quality of medical services. For example, Handayani (2014) utilizes the components of the SERVQUAL model to determine the quality of medical services, whereby the customer has to evaluate the components for the selection of a medical institution.

The second one aimed to apply the SERVQUAL model to medical services through its modification or extension, or to develop a similar component model. For example, Edvardsson (1989) developed a four-component model that made up the quality of medical services, which were consisted of technical quality, interactive quality, and functional quality. The last one takes a comprehensive approach which tries to grasp all the factors affecting the purchase of a medical service from a broader point of view

The existing studies have presented a wide range of factors determining the quality of medical service. It is needed to integrate and classify them in a systematic and concise way. This paper presents a conceptual framework for classifying various determinants 
into three hierarchical categories, and examines the categories' influences on a customer's intention to purchase a medical service. The categories will be empirically verified by using data from Chinese medical tourists in Korea. At the same time, the role of an invasiveness of treatment is additionally explored as a moderating variable. It is expected that depending on the type of medical services to be purchased, an invasiveness of treatment will play a moderating role between quality of a medical service and customer's purchase intention.

This paper is structured as follows. In Section 2 the paper reviews the literature on the determinants of medical service quality. A conceptual framework and hypotheses are developed in Section 3. Methodological aspects are discussed in Section 4. Section 5 discusses the results of the statistical analysis and findings, and Section 6 discusses the implications and limitations of the study.

\section{Literature Review}

One purpose of this study is to figure out what becomes an important decision factor when purchasing medical service, especially foreign medical service. To answer this question, the existing researches are based on one of the following theoretical backgrounds.

First, the SERVQUAL model (Parasuraman, et al., 1985,1988) which was used widely in a service industry is also applied to measure the quality of medical services. The model's components were borrowed to measure the quality of medical services.

For example, Handayani (2014)has drawn four dimensions from the SERVQUAL model including people, process, infrastructure and policy ones, and examined the effect of these dimensions on a customer's hospital selection. People dimension consists of empathy and professionalism, and process dimensions mean responsiveness and reliability. Infrastructure dimension is composed of tangibility, and lastly policy dimension means reliability. The result of this paper indicates that people and process are the most important factor affecting the quality of medical services.

Second, even if the SERVQUAL model has been widely used in the field of service, the dimensions' validity for measuring the quality of service has received a lot of criticism (Lopez-Toro, et al., 2010). As a result, some researchers modified those dimensions suitable to their research purpose.

Other researchers developed completely different models. For example, Edvardsson, et al., (1989) suggested that medical service quality could be divided into technical quality, integrative quality, functional quality and outcome quality. Dagger et al. (2007) also developed different dimensions to evaluate healthcare service quality which contain interpersonal quality, technical quality, environment quality, and administrative quality. First, interpersonal quality refers to manner, communication, and relationship. Second, technical quality consists of expertise and outcome. Third, atmosphere and tangibles quality are the important factor of environment quality. Finally, administrative quality includes timeliness, operation, and support. They argued these four factors were important in selecting a medical institution.

Last, some studies take a comprehensive approach which tries to grasp all the factors affecting the purchase of a medical service from a broader point of view. These studies have tried to found out macro-level as well as micro-level factors influencing a medical service purchase. Macro-level factors include such as national image and healthcare policy, cultural similarities and differences, tourism infrastructure, and so on. Micro-level ones are those related with service producers (or providers) like the SERVQUAL model. Or, quite a contrary to the comprehensiveness, it concentrates on a specific micro-level concept (e.g., brand awareness) in order to explain a customer behavior of the medical service purchase. 
Kang and Oh (2008), Chun and Lee (2010) and Park, et al., (2012) are typical cases taking a comprehensive approach. These studies investigated foreigner's considerations when using Korean medical services. They tried to investigate why the foreigners decided to visit South Korea as a medical tourist destination, or how they chose a certain medical institution. The common determinants revealed by these studies include national health policy and support systems, medical tourism infrastructure, medical institution's brand awareness, doctors and staff expertise, and hospital management.

\section{A Conceptual Framework and Hypotheses}

Existing studies have presented a wide range of factors determining the quality of medical service. But some factors are conflicting with and overlapping each other in an operational point of view. It is needed to integrate and classify them in a systematic and concise way. As shown in $<$ Figure $1>$, the conceptual framework is suggested which classifies a wide range of influencing factors into three hierarchical categories. In Figure 1the quality of a medical service is subdivided into three components, that is, a core service, an extended service and a tangible service.

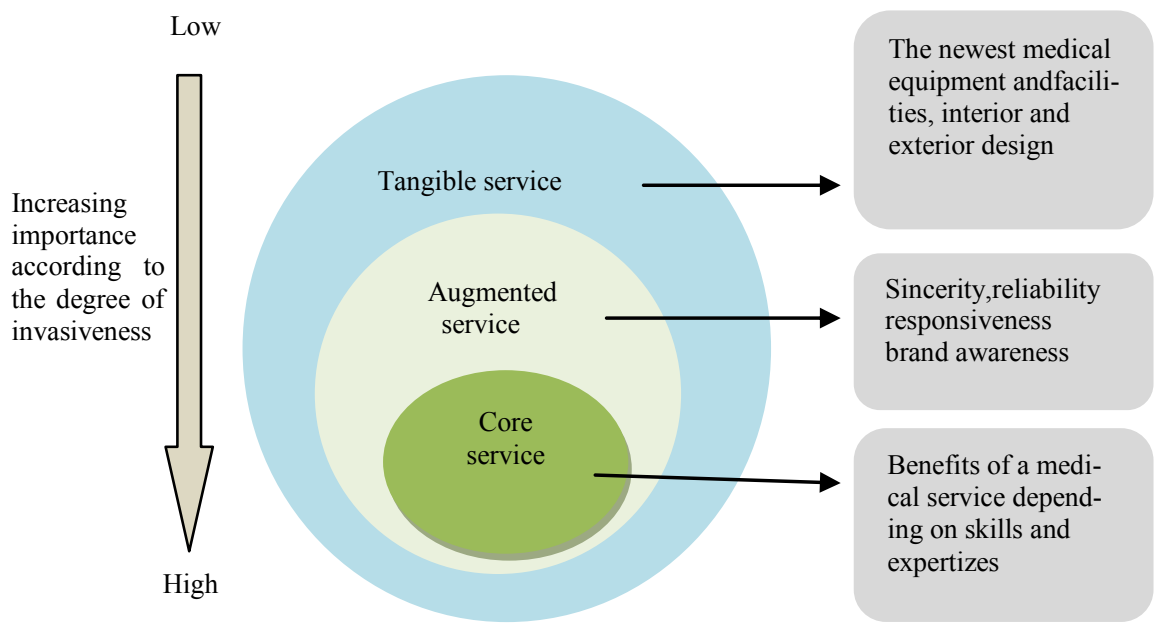

Figure 1. A Classification of Medical Service Quality

Firstly, a core service refers to generic benefits that customers get actually through medical services. For example, people want to be more beautiful from a plastic surgery. Their desire could be satisfied depending on skills and expertise of a physician in charge of a treatment or a surgery.

Secondly, an augmented service means a provider's attitude and a contextual atmosphere in which a core service is provided. Even if medical institutions provide a similar level of core services, each patient's level of satisfaction is different from hospital to hospital according to a provider's attitude which could be sincere or not.

Lastly, a tangible service refers to instrumental tools or physical infrastructures used to provide a core service. Medical equipment and IT appliances needed for diagnoses and treatments fall in this category. Medical institutions' facilities such as hospital's amenities, exterior and interior designs, and parking lots are corresponding to physical infrastructures.

Various determinant factors of the quality of a medical service are included in one of these three categories. These categories can be ranked in a hierarchical order according to the relative importance that customersthink on purchasing medical services. The importance of each category is expected to change according to the degree of invasiveness. 
Invasiveness is defined as 'relatedness to a medical procedure in which a part of the body is entered, as by puncture or incision.' Invasive treatments hurt, or cause damage to a customer more than non-invasive treatments. As the degree of invasiveness is increasing, it is expected that customers will think a core and an augmented service becomes more important than a tangible service.

The above conceptual framework helps to narrow various factors affecting a medical service purchase down to three categories. This framework could be utilized to clearly distinguish the dimensions that overlap or conflict in the traditional studies. For example, a study utilizing the SERVQUAL model usually focused on a micro-level dimension, or a tangible and an augmented service. But a micro-level or a provider-related dimension is not enough to measure the quality of a medical service. The model's dimensions need to be reclassified and adjusted according to the service type, industry characteristics, and situation so that they can reflect the uniqueness of each service. This newly developed framework could complement the limitation.

To evaluate the framework's explanatory power, it is required to examine whether each category of a medical service really affects patients' purchase of medical service. To examine each category's practical explanatory power, the following hypotheses are proposed.

Hypothesis 1: A core service of a medical institution will have a positive impact on a customer's intention to purchase a medical service from it.

Hypothesis 2: An augmented service of a medical institution will have a positive impact on a customer's intention to purchase a medical service from it.

Hypothesis 3: A tangible service of a medical institution will have a positive impact on the customer's intention to purchase a medical service from it.

Meanwhile, an invasiveness of treatment is introduced in order to examine the relative importance of explaining variables depending on the type of medical services to be purchased. The intensity of invasive therapies is anticipated to change the strength of explaining variables for selecting a medical institution. For example, a customer who tries to purchase a highly invasive medical service will consider core and augmented services as more important factors. That is, staff's expertise and medical technique (core services), or brand awareness and reliability (augmented services) will be regarded as more important than hospital's amenities or convenience parking lots (tangible services). On the other hand, the importance of medical professionalism is expected to be lower when a noninvasive treatment is required. Therefore, the degree of invasiveness will act as a moderating variable between the quality of medical services and medical institution selection.

The degree of invasiveness will be measured in a dichotomous way by categorizing the types of medical services into an invasive medical treatment and a non-invasive medical one. It is intended to examine whether there are any differences in the relative importance of variables between an invasive and a non-invasive treatment when customers select medical institutions. Therefore, it is expected as follows:

Hypothesis 4: The degree of invasiveness will moderate the relationship between the quality of medical service and a customer's intention to purchase.

Hypothesis 4-1: When an invasive treatment is purchased, a core service of a medical institution will have a more positive impact on a customer's intention to purchase a medical service from it.

Hypothesis 4-2: When an invasive treatment is purchased, an augmented service of a medical institution will have a more positive impact on a customer's intention to purchase a medical service from it. 
Hypothesis 4-3: When an invasive treatment is purchased, a tangible service of a medical institution will have a less positive impact on a customer's intention to purchase a medical service from it.

\section{Data Collection and Measurements}

A questionnaire was used for data collection. A survey was conducted by targeting the Chinese visiting in the city of Busan and Daegu in Korea. The Chinese people were targeted as the investigated subjects since they took the largest portion of foreign visitors in Korea in 2013 whose purpose is for the medical tourism.

A convenient sampling method was adopted to select a respondent who has been confirmed to be Chinese in the neighborhood of Busan and Daegu areas. Total survey spansthe period from September 1, 2014 to November 30.A total of one hundred twenty-seven questionnaires were collected by distributing three hundred, but after excluding insufficient responses, final questionnaires used for statistical analysis totaled one hundred sixteen.

The demographic statistics were used to examine the characteristics of the respondents as follows.

The majority of respondents $(N=71,61.2 \%)$ were female. With regard to age distribution, the highest frequency $(N=88,75.8 \%)$ was $20 \mathrm{~s} ; 10.4 \%(N=12)$ was $30 \mathrm{~s} ; 9.49 \%(N=11)$ was $40 \mathrm{~s} ; 4.3 \%(N=5)$ was $50 \mathrm{~s}$. With regards to education level, the majority of the respondents were university students $(N=39,33.6 \%)$; college graduates $(N=23,19.8 \%)$; college students $(N=23,19.8 \%)$; and high school students $(N=17,14.7 \%)$.

To gather subjective measures of variables, respondents were requested to rate five operational measures of institutions' medical service quality, one measure of treatment invasiveness, and one measure of a customer's purchase intension. All of which were adopted from previous studies. Table1 summarizes the operational measures and their related studies.

Table 1. Operational Measures

\begin{tabular}{|c|c|c|}
\hline Construct & Items & References \\
\hline $\begin{array}{l}\text { Augmented } \\
\text { service } \\
\text { (brand } \\
\text { awareness) }\end{array}$ & $\begin{array}{l}\text { Familiarity with its institutions(BA1) } \\
\text { Easily remembered as a medical } \\
\text { institution(BA2) } \\
\text { Perceived as being different from } \\
\text { other medical institutions(BA3) } \\
\text { Being remembered as a good im- } \\
\text { age(BA4) }\end{array}$ & $\begin{array}{l}\text { Aaker(1996); } \\
\text { Keller(2001) }\end{array}$ \\
\hline $\begin{array}{l}\text { Augmented } \\
\text { service } \\
\text { (responsiveness) }\end{array}$ & $\begin{array}{l}\text { Providing sufficient answers(RE1) } \\
\text { Fast performance for your require- } \\
\text { ments(RE2) } \\
\text { Kindness of the doctors and medical } \\
\text { staff(RE3) }\end{array}$ & $\begin{array}{l}\text { Handayani, } \\
\text { Hidayanto, } \\
\text { Sanhyaduhita, } \\
\text { Kasiyah, } \\
\text { Ayuingtyas } \\
\text { (2014) }\end{array}$ \\
\hline $\begin{array}{l}\text { Augmented } \\
\text { service } \\
\text { (reliability) }\end{array}$ & $\begin{array}{l}\text { Empathy of medical staff(RL1) } \\
\text { Commitment of staff(RL2) } \\
\text { Heartfelt service(RL3) }\end{array}$ & $\begin{array}{l}\text { Dagger, Swee- } \\
\text { ny, and John- } \\
\text { son } \\
(2007)\end{array}$ \\
\hline $\begin{array}{l}\text { Tangible } \\
\text { service } \\
\text { (physical } \\
\text { characteristics) }\end{array}$ & $\begin{array}{l}\text { Modern design of hospital build- } \\
\text { ings(PC1) } \\
\text { Completeness of the internal facili- } \\
\text { ties(PC2) } \\
\text { Convenience of parking spaces(PC3) } \\
\text { Convenience of Facilities(PC4) }\end{array}$ & $\begin{array}{l}\text { Siu, Wan and } \\
\text { Dong } \\
(2012) \text {; } \\
\text { Weise, } \\
(2008)\end{array}$ \\
\hline $\begin{array}{l}\text { Core service } \\
\text { (professionalism) }\end{array}$ & $\begin{array}{l}\text { Staff's reputation(PF1) } \\
\text { Medical skill levels of staff(PF2) } \\
\text { The latest of the hospital equip- }\end{array}$ & $\begin{array}{l}\text { Siu, Wan, and } \\
\text { Dong } \\
(2012)\end{array}$ \\
\hline
\end{tabular}




\begin{tabular}{lll} 
& $\begin{array}{l}\text { ment(PF3) } \\
\text { Certification of medical institu- } \\
\text { tions(PF4) }\end{array}$ & \\
$\begin{array}{l}\text { Invasive vs. non- } \\
\text { invasive }\end{array}$ & $\begin{array}{l}\text { Degree of invasive medical treatment } \\
\text { (DI) }\end{array}$ & $\begin{array}{l}\text { Bookman and } \\
\text { Bookman } \\
(2007)\end{array}$ \\
$\begin{array}{l}\text { Purchase } \\
\text { intention }\end{array}$ & $\begin{array}{l}\text { Positive recommendation(CI1) } \\
\text { Purchase possibilities(CI2) }\end{array}$ & $\begin{array}{l}\text { Jacoby and } \\
\text { Chestnut } \\
\text { Preference(CI3) }\end{array}$ \\
& & Oliver(1999) \\
\hline
\end{tabular}

One native speaking individual translated the questionnaire into Chinese. One other individual then back translated the questionnaire into Korean. Translation and backtranslation procedures (Luo, 2010) ensure the consistency of the Chinese and Korean versions of the questionnaire.

Respondents evaluated each measure of medical service quality on a scale of 1 (when you choose a medical institution) "it is not important" to 5 "it is very important." The invasiveness was categorized on a scale of 0 "a non-invasive medical treatment was purchased" to 1 "an invasive medical treatment was purchased." Finally, each measure of purchase intention was evaluated on a scale of 1 "I do not agree at all" to 5 "I do agree completely."

\section{Empirical Analysis}

\subsection{Reliability and Validity Verification}

In this paper, Cronbach's alpha was calculated to check the reliability of measureditems. As shown in $<$ Table 2>, all Cronbach's alpha were above 0.6 except two items (BA4, PF4), which were eliminated from the final analysis. After dropping two items, reliability alphas ranged from 0.6 to 0.8 were highly acceptable.

In order to facilitate the interpretation between factors and variables, orthogonal rotation VARIMAX method was utilized. Factor loadings on a core service, an augmented service and a tangible service were greater than 0.7 except two variables (BA2, RE3), and were acceptable so as to ensure the validity. And factor loading on purchase intention was greater than 0.7 .

\subsection{Regression Analysis}

This research employs an OLS regression analysis to determine the validity of the hypotheses H1-H3. Results of an OLS regression analysis testing hypotheses $\mathrm{H} 1-\mathrm{H} 3$ are shown in Table 3 . The $R^{2}$ value that indicates the explanatory power of regression equation showed a relatively highly $47.6 \%$. F-value as the test result of variance analysis for the significance of the regression equation also shows a statistically significant fit $(\mathrm{p}<$ $0.001)$.

About the effect of the independent variables, the regression results show that three independent variables are statistically significant. Professional services reflecting a core service is significantly $(\mathrm{p}<0.01)$ and positively $(B=0.571)$ related to purchase intention: thus, supporting Hypothesis 1 . Both of brand awareness $(B=0.117, \mathrm{p}<0.05)$ and reliability $(B=0.087, \mathrm{p}<0.05)$ are also significantly and positively related to purchase intention, but responsiveness is not significant: thus, partially supporting Hypothesis 2.

Table 2. Reliability and Validity Test

\begin{tabular}{|c|c|c|c|c|c|}
\hline Items & Factor1 & Factor2 & Factor3 & Factor4 & Factor5 \\
\hline Augment- $\quad$ BA1 & .792 & .054 & .122 & .072 & .184 \\
\hline
\end{tabular}




\begin{tabular}{|c|c|c|c|c|c|c|}
\hline \multirow{8}{*}{$\begin{array}{c}\text { ed } \\
\text { service } \\
\text { (AS) }\end{array}$} & BA2 & .548 & .122 & .331 & .065 & .167 \\
\hline & BA3 & .731 & .200 & -.063 & .225 & .037 \\
\hline & RE1 & .223 & .832 & .024 & .021 & -.062 \\
\hline & RE2 & .151 &.$\overline{702}$ & .119 & .096 & .300 \\
\hline & RE3 & -.075 &.$\overline{565}$ & .092 & .091 & .475 \\
\hline & RL1 & .172 & .017 & .762 & .133 & .178 \\
\hline & RL2 & -.082 & .022 & .781 & .161 & .256 \\
\hline & RL3 & .173 & .138 & .756 & .151 & -.151 \\
\hline \multirow{4}{*}{$\begin{array}{l}\text { Tangible } \\
\text { service } \\
\text { (TS) }\end{array}$} & PC1 & -.160 & .134 & .273 & .767 & .091 \\
\hline & PC2 & .317 & -.020 & .006 & .796 & .018 \\
\hline & PC3 & -.089 & .124 & .144 & .852 & .061 \\
\hline & PC4 & .336 & -.036 & .102 & .785 & -.088 \\
\hline \multirow{3}{*}{$\begin{array}{l}\text { Core } \\
\text { service } \\
\text { (CS) }\end{array}$} & PF1 & .161 & .107 & .024 & $-\overline{-.020}$ & .779 \\
\hline & PF2 & .118 & .157 & .119 & .031 & .769 \\
\hline & PF3 & .072 & .032 & .092 & .032 & .837 \\
\hline \multicolumn{2}{|c|}{ Eigen value } & 4.211 & 2.415 & .1569 & 1.408 & 1.149 \\
\hline \multicolumn{2}{|c|}{$\begin{array}{l}\text { Explained } \\
\text { variance }\end{array}$} & 26.319 & 15.092 & 9.805 & 8.802 & 7.180 \\
\hline \multicolumn{2}{|c|}{$\begin{array}{c}\text { Cumulative } \\
\text { variance }\end{array}$} & 26.319 & 41.411 & 51.216 & 60.018 & 67.198 \\
\hline \multicolumn{2}{|c|}{ Cronbach's alpha } & .663 & .790 & .687 & .839 & .688 \\
\hline
\end{tabular}

Table 3. Results of OLS Regression Analysis

\begin{tabular}{|c|c|c|c|c|c|c|}
\hline \multirow{2}{*}{\multicolumn{2}{|c|}{ Variables }} & \multicolumn{5}{|c|}{ Purchase Intention } \\
\hline & & \multirow{2}{*}{$\begin{array}{c}\text { Coefficient } \\
.117\end{array}$} & \multirow{2}{*}{$\begin{array}{c}\begin{array}{c}\text { Standardized } \\
\text { Error }\end{array} \\
.037\end{array}$} & \multirow{2}{*}{\begin{tabular}{|l} 
t-value \\
$3.122^{* *}$
\end{tabular}} & \multirow{2}{*}{$\begin{array}{c}R^{2} \\
\left(\operatorname{adj} .-R^{2}\right)\end{array}$} & \multirow{2}{*}{$\begin{array}{c}F \\
47.637^{* * *}\end{array}$} \\
\hline AS & $\overline{\mathrm{BA}}$ & & & & & \\
\hline & RE & .059 & .044 & 1.337 & & \\
\hline & RL & .087 & .041 & $2.135^{* *}$ & & \\
\hline TS & $\mathrm{PC}$ & .002 & .046 & .049 & & \\
\hline CS & $\mathrm{PF}$ & .571 & .052 & $11.047 * * *$ & & \\
\hline
\end{tabular}

AS: augmented service, TS: tangible service, CS: core service, BA: brand awareness RE: responsiveness, RL: reliability, PC: physical characteristics, PF: professionalism ${ }^{\star}: \mathrm{p}<0.1,{ }^{* *}: \mathrm{p}<0.05,{ }^{* * *}: \mathrm{p}<0.01$

\subsection{Moderating Effect of the Degree of Invasiveness}

To determine the validity of the hypotheses H4, a hierarchical OLS regression analysis is prepared. The results of the hierarchical OLS regression models are shown in $<$ Table $4>$. Two regression models were run. Model 1 examines the effects of the independent variables on consumer's purchase intention. Model 2 tests the moderating effects of treatment invasiveness on the relationship between service quality and purchase intention.

Table 4. Degree of Invasiveness as a Moderator Variable

\begin{tabular}{|c|c|c|c|c|}
\hline & \multicolumn{2}{|c|}{ Model 1} & \multicolumn{2}{|c|}{ Model2 } \\
\hline & $\beta$ & t-value & $\beta$ & t-value \\
\hline BA & .117 & $3.122 * * *$ & -.342 & $-2.216 * *$ \\
\hline $\mathrm{RE}$ & .059 & 1.337 & -.198 & -.599 \\
\hline RL & .087 & $2.135 * *$ & .032 & .214 \\
\hline $\mathrm{PC}$ & .002 & .049 & -.599 & $-2.492 * *$ \\
\hline PF & .571 & $11.047 * * *$ & .365 & $1.860^{*}$ \\
\hline $\mathrm{BA} * \mathrm{DI}$ & & & .090 & $2.646 * *$ \\
\hline RE*DI & & & .133 & $2.564 * *$ \\
\hline SL*DI & & & -.004 & -.110 \\
\hline PC*DI & & & -.021 & -.498 \\
\hline $\mathrm{PF} * \mathrm{DI}$ & & & -.024 & -.528 \\
\hline$R^{2}$ & \multirow{2}{*}{\multicolumn{2}{|c|}{.437}} & \multicolumn{2}{|c|}{.749} \\
\hline$\Delta R^{2}$ & & & \multicolumn{2}{|c|}{.312} \\
\hline$F$ & \multicolumn{2}{|c|}{$47.637 * * *$} & \multicolumn{2}{|c|}{$90.671 * * *$} \\
\hline$\Delta F$ & & & \multicolumn{2}{|c|}{43.034} \\
\hline$F^{2}$ & & & \multicolumn{2}{|c|}{.554} \\
\hline
\end{tabular}


Dependent variable is purchase intention. $F=90.671, \mathrm{p}<.001, R^{2}=.758$, adj. $R^{2}=.749$

$*: \mathrm{p}<0.1, * *: \mathrm{p}<0.01, * * *: \mathrm{p}<0.001$

BA: brand awareness, RE: responsiveness, RL: reliability, PC: physical characteristics

PF: professionalism, DI: degree of invasiveness

As shown in Table, the overall model fit results (F-statistics) of two models are very significant (in both case, $\mathrm{p}<0.001$ ), which is a finding that attests to the overall robustness of these models. The change of $R^{2}$ is examined, which are contributing to the influence on customer's purchase intention. With the inclusion of five interaction terms, $R^{2}$ was increased substantially from 0.437 to 0.749 . This suggests that there was substantial increase in the variance explained after adding the treatment invasiveness interactions.

With regard to the moderating effects, $<$ Model $2>$ examines the role of the invasiveness as a moderator between five independent variables (brand awareness, responsiveness, reliability, tangibility and professionalism) and one dependent variable (customer's purchase intention). The two interactions, i.e., BA (brand awareness)*DI (degree of invasiveness) and RE (responsiveness)*DI (degree of invasiveness), in Model 2 are positively and significantly associated with purchase intention. These results can be interpreted as follows: First, when customers purchase invasive treatments, a medical institution's brand awareness will have a more positive impact on their intention to purchase from it. Second, when customers purchase invasive treatments, a medical institution's responsiveness will have a more positive impact on their intention to purchase from it. Both results are empirical evidences supporting Hypothesis 4-2.

The remaining three interactions do not show any significant result, thus they do not support Hypothesis 4-1 and 4-3. In conclusion, Hypothesis 4 was partially supported.

\section{Conclusion}

Existing studies have suggested a wide range of factors determining the quality of medical service. Since some factors are conflicting with and overlapping each other, it is needed to integrate and classify them in a systematic and concise way. This paper presents a conceptual framework for organizing various determinant factors into three hierarchical categories.

Three hypotheses were proposed to examine whether each category of medical servicereally affects patients' purchase of medical service and one was to examine the moderating variable of an invasiveness of treatment. Depending on the type of medical services to be purchased, an invasiveness of treatment will play a moderating role between the quality of medical service and customer's purchase intention.

The empirical results can be summarized as follows. First, the core service (expertise) and the augmented services (brand awareness and reliability) have been found to be important factors in influencing a customer's purchase intention. Second, the results also hint that the degree of invasiveness plays a moderating role between service quality (brand awareness and responsiveness) and purchase intention. Therefore, considering the relative importance of the medical services according to the degree of invasive medical services, its practical implication needs to be reflected in the marketing approach of medical institutions.

In relation to implications for theory, this study has contributed to the following aspects. First, in relation to the quality of medical service, this study is the first in developing a conceptual framework that classify a wide range of determinants into hierarchical categories. Second, the concept of invasiveness was introduced into the academic discussion. The determinants of a medical service quality can be evaluated in a more practical contextand from a more sophisticated perspective. This finding results in advancing our understanding of medical service quality.

This study has limitations. It adopted a convenient sampling procedure on the Chinese 
tourists in Korea. The representativeness of samples collected is not guaranteed, and the number of samples is not sufficient for the general interpretation of this study.

\title{
References
}

[1] D. A. Aaker, "Building Strong Brand", New York: Free Press,(1996).

[2] M. Z. Bookman and K. R. Bookman, "Medical Tourism in Developing Countries", New York: Palgrave Macmillan, (2007).

[3] H. J. Chun and H. S. Lee, "Market segmentation of overseas medical tourism and attributes of medical tourism destination", Tourism \&Leisure Research, vol.22, no.6,(2010), pp.7-23.

[4] T. S. Dagger, J. C. Sweeney and L. W. Johnson, "A hierarchical model of health service quality: Scale development and investigation of an integrated Model", Journal of Service Research, vol.10,(2007), pp. 123.

[5] B. Edvardsson, A. Gustavsson, M. D. Johnson and B. Sandén, "New Service Development and Innovation in New Economy", Lund, Sweden: Studentlitteratur, (2000).

[6] P. W. Handayani, A. N. Hidayanto, P. I. Sandhyduhita and K. D. Ayuningtyas, "Strategic hospital services quality analysis in Indonesia", Expert Systems with Applications, vol.42,(2015), pp.3067-3078.

[7] J. Jacoby and R. W. Chestnut, "Brand Loyalty: Measurement and Management", New York: John Wiley and Sons,(1978).

[8] J. J. KangandS. H. Oh, "An exploratory analysis of demographic differences on choice of medical tourism destination," Tourism \& Leisure Research, vol.20, no.4, (2008), pp.139-158.

[9] K. L. Keller, "Building customer-based equity," Marketing Management,(2001) July/August, pp.15-19.

[10] M. S. Kim and H. Y. Bang, "Influencing factors on the choice of foreign medical institutions and a moderating effect of an invasive treatment," Advanced Science and Technology Letters, vol.102,(2015), pp.64-69.

[11] A. A. Lopez-Toro, R. Diaz-Munoz and S. Perez-Moreno, "An assessment of the quality of a tourist destination: The case of Nerja, Spain,” Total Quality Management, vol.21, no.3,(2010), pp.269-289.

[12] Y. Luo, "Determinants of entry in an emerging economy: A multilevel approach," Journal of Management Studies, vol. 38, no. 3,(2010), pp. 443-472.

[13] R. L. Oliver, "Whence customer loyalty", Journal of Marketing, vol.63,(1999), pp.33-40.

[14] A. Parasuraman, V. A. Zeithaml and L. L. Berry, "A conceptual model of service quality and its implication for future research," Journal of Marketing, vol. 49,(1985), pp.41-50.

[15] A. Parasuraman, V. A. Zeithaml and L. L. Berry, "SERVQUAL: A multiple-item scale for measuring customer perceptions of service quality," Journal of Marketing, vol.64, no.1,(1988), pp.12-40.

[16] H. P. Park, "An empirical study on the destination choice attributes, satisfaction, and behavioral intention of medical tourism in Korea," Korean Journal of Business Administration, vol.25, no.1,(2012), pp.131-146.

[17] N. Y. Siu, P. Y. K. Wan and P. Dong, "The impact of the service scape on the desire to stay in convention and exhibition centers: The case of Macao," International Journal of Hospitality Management, vol.31,(2012), pp.236-246.

[18] E. Weise, "Chilly rooms anger people at conferences, social events," USA Today,(2008) August 6.

\begin{abstract}
Author
Min-Sook Kim, (PH. D., Pusan National University, Korea) is an assistant professor at the Keimyung University, Korea. Her research interests are in international business, global marketing strategy and medical tourism. She published two books, Medical Tourism (2011), Strategic Management (2014). She has published a lot of papers in several academic journals in Korea.

Ho-Yeol Bang, (PH. D., Korea University, Korea) is a professor at the Pusan National University, Korea. His research interests are in international business, strategic management, and knowledge management. He published several books including International Business (2008) and Strategic Management (2014). His research work has been published in numerous academic journals in Korea and USA.
\end{abstract}


International Journal of $u-$ and e- Service, Science and Technology Vol.8, No. 9 (2015), pp.1-14 